\title{
Unmet Need for Family Planning Contraceptive Methods among Mothers Attending Family Health Centers at Ismailia City
}

\author{
Heba Al-kotb \& Hanaa Kasem Farag \\ Lecturer of Community health nursing department, Faculty of Nursing, Suez Canal University, Egypt. \\ Lecturer of Community health nursing department, Faculty of Nursing, Suez Canal University, Egypt.
}

\begin{abstract}
Background: Population growth in Egypt continues to be high. This increase could be attributed to many factors include having unmet need for family planning. Aim of the study; the present study aimed to assess unmet need for family planning contraceptive methods among mothers attending family health center at Ismailia city.

Design: A cross sectional descriptive design was used in this study by adopting quantitative and qualitative methodology. Setting: the study was conducted in seven family health centers located in Ismailia city.

Sample: convenience sample of 371 from mothers attending in family health center who fulfilled the study inclusion criteria. Tools: Two tools were used in the present study; The first tool was a structured interview questionnaire consisted of three parts. The second tool was focus group discussion guide to identify and explain factors related to unmet family planning. Results; The results revealed that the most common reasons for unmet need family contraceptive methods among mothers were fear of side effects, lactation amenorrhea and wanted another pregnancy. Conclusion; There were many factors related to unmet needs family planning contraceptive methods as cognitive, culture and sexual relation factors Recommendation; family planning counseling for mothers during prenatal and postnatal period.
\end{abstract}

\section{Keywords: Unmet Need, Contraceptive Methods \& Family Planning.}

\section{Introduction}

Family planning is the deliberate prevention of unplanned pregnancy through the use of different devices, sexual practices, chemicals, or surgical procedures. There are several types of family planning methods that are officially described as such because they have shown reliability in contraception (Ayiasi et al., 2015, Elweshahi et al., 2017).

Access to safe family planning is a human right. Family planning is essential to achieving gender equality and the empowerment of women, a key factor in poverty reduction. Married women of childbearing age can be classified according to their need for contraception into four main categories: without the need to be unmarried; without the need for immediate pregnancy, without the need for current contraceptives (need) and with unmet need for contraceptive (Choi et al., 2016, Jain et al., 2014).

Unmet need for family planning points to the gap between women's reproductive desire to avoid pregnancy and contraceptive behavior (Kashyap et al., 2017, El Shazly et al., 2016, Jain \& Winfrey, 2017). The level of unmet needs is one of the standard indicators for measuring the impact of a family planning program in any country(Sudha et al., 2017, Cleland et al., 2014). This indicator provides information on the size of a critical subgroup of population for family planning programs. They represent women at the risk of pregnancy with obvious need for FP services. These

women are willing to reduce or give birth in the future, and they do not use FP methods. Such women have an unmet need (unmet demand) for FP and are the logical primary target for program efforts (Elweshahi et al., 2017, Machiyama \& Cleland, 2014).

Unintended and mistimed pregnancy is the usual consequences of having unmet need for FP. Globally by world health organization (WHO) an estimated 80 million unintended pregnancies, both mistimed and unwanted, occur each year. Unintended pregnancy and births have grave effect on the mother, family, global social and health burdens. It is much more likely to end in potentially unsafe abortion (Organization, 2012, Elweshahi et al., 2017, ElMoselhy et al., 2017).

The EDHS 2014 reported that many Egyptian women are having more births than they consider ideal. Overall, $14 \%$ of pregnancies in the five years prior to the survey were reported unwanted. Among those, $5 \%$ of births were identified as mistimed postpartum family planning (PPFP) and this initiation of family planning services within the first 12 months following childbirth (El-Moselhy et al., 2017, Elweshahi et al., 2017, Mohsen et al., 2016). Birth spacing through the first 12 months following childbirth are known to be associated with the highest risk of adverse health outcomes for both mother and 
infant (Sitruk-Ware et al., 2016, El-Moselhy et al., 2017). Postpartum women are more likely to have unmet need for family planning as compared to all married women. Unmet need for PPFP during the first year after birth accounted for $71 \%$ of the total unmet need for spacing among women in Alexandria governorate according to a study conducted by (Elweshahi et al., 2017). There is another several studies illustrate that the most of the families overlook FP methods following childbirth. This might be due to lack of awareness of pregnancy risks, difficulty in accessing services, and sociocultural issues. Other possible factors include geographical and financial inaccessibility, provider bias, and poor method choice, lower status of women, medico-legal restrictions and fear of side effects (Sudha et al., 2017, Kashyap et al., 2017, El Shazly et al., 2016).

\section{Significant of the study}

Population growth in Egypt continues to be high. Recent increase in total fertility predicts more future increase. This increase could be attributed to many factors include having unmet need for FP (Choi et al., 2016). Urgent steps are required to make FP methods more widely available, accessible and affordable. EDHS always reports data on to unmet need for family planning among total number of married women in the reproductive age but it gives no data about such estimate for post-partum women (Jain et al., 2014). Promotion of family planning in countries with high birth rates have the potential to avert 32\% of maternal deaths (Choi et al., 2016). Nurses are able to "encourage specific actions such as the initiation and continuation of using contraceptive methods (Vural et al., 2016), thus helping many women and couples avoid negative health outcomes associated with having babies too close together"(Sarayloo et al., 2015).

\section{Aim of this study}

The aim of this study was to assess unmet need for family planning contraceptive methods among mothers attending family health center at Ismailia city.

\section{Research question}

- What are the reasons of unmet need for family planning contraceptive methods among mothers?

- What are the factors related to reasons of unmet needs for family planning contraceptive methods among mothers?

\section{Study design}

The researchers used a cross sectional descriptive research design to conduct this study by adopting quantitative and qualitative methodology (phenomenological explanatory sequential design).

\section{Explanatory Sequential Design}

Explanatory sequential design emphasis quantitative analysis, followed with semi-structured in-depth interviews (qualitative measures) to help explain the quantitative results.

\section{Setting}

The study was conducted in seven family health centers in Ismailia city (one in each district). The family health centers was conducted are El Shahda, Sheikh Zayed, Al Salam, Seven Girls, Alaraishia center, Future center ,Abu-attoa center.

\section{Sampling}

Two samples were used in this study according to design (qualitative and quantitative).

\section{Quantitative sample}

Convenience sample of women in the previous family health centers mentioned who fulfill the study criteria and available at the time of data collection were included in the study subjects, their number amounted to 371 woman.

\section{Inclusion criteria of the study subject}

(1)Women aged 20 years to 45 years; and (2) nonuse contraceptive method (3), and during one year postpartum (4) accept to participate in the study

\section{Sampling technique}

The technique used to select the sample was; Postpartum mothers attending the family health centers for attending public immunization settings delivering routine immunization for infants in Ismailia at the day of vaccination against Measles, Mumps and Rubella (MMR) according to EPI schedule in Egypt.

Subjects for qualitative data

In this study the researchers used a subset of mothers from the first survey phase and dig deeper into unmet family planning methods. Three focus group discussion (FGDs) were conducted in the previous setting for mothers. Each focus group composed of 67 mothers. In addition, two groups discussion from doctors and community healer working in previous setting to identify your opinions regarding unmet need family planning contraceptive methods.

Tools:

Tool 1: Mothers interviewing questionnaire: it include three parts:

Part (1): socio-demographic data include, age, level of education, occupation, etc.

Part (2): post natal history includes menstrual history, mode of deliveries, and number of abortion.

Part (3): Previous use of family planning contraceptive method and reasons for unmet need for family planning methods.

Tool II: Focus group discussion guide:

Focus group discussion guide was developed by the researcher to collect the qualitative data from the 
mother to identify and explain factors related to unmet family planning. Taking into consideration the population group, questions were short, unambiguous, and open ended. The semi-structured nature of the interview guide ensured and flexibility as the discussion unfolded within each focus group. After the first day of focus groups, the researches met each other to discuss the guide and modifications were made to improve clarity. The final guide questions which include predisposing factors related to unmet need of FP contraceptive methods as cognitive, culture and health condition. Furthermore, contraceptive method itself, sexual relation factors and family planning services.

\section{Method}

- An official letter from faculty of nursing, Suez Canal University was directed Egypt, and sent to the directors of family health centers to get their permission for data collection from the authorized personal. The letters explained the purpose of the study, and sought their cooperation.

- Data were collected during the first of January 2015 to the end of May 2016.

- The tools 1 (part 1-3) were developed by the researchers after thorough review of the literature and translated into Arabic. This tool tested and revised by five experts in the related fields of the community health nursing for content validity. Necessary modifications were done accordingly.

- Reliability of tool I was asserted using the Cronbach's Alpha Coefficient, it was 0.91

- A pilot study on a number of 30 women, who are excluded from the main study's subject, was carried out to test the feasibility and the applicability of the tools.

- Before starting the data collection, the agreements and the aim of the study were explained to each head of nursing at family health centers to gain their cooperation.

- The researcher met the subjects in the waiting room, in each selected family health center. The researcher introduced herself and explained to the mothers the aim of the study and their consent to participate was obtained.

- Each mother was personally interviewed and sometimes groups of mothers (minimum one woman and maximum six women) in the family health center. The interview lasted for from 9:3011:30 AM, three times per week, in a period of 5 months.

\section{Qualitative study}

- We conducted five in-depth interviews among mothers from different family health centers mentioned before were purposively selected for focus group discussion.
- The study mothers were informed briefly about the purpose of the study and written informed consent was taken. Data collected by researchers and note taker and voice recorder. The qualitative data were collected in the quietest corner of the family health center compound that gives optimum privacy and focused on factors related to unmet need of family planning contraceptive methods. Therefore interviews took 45-60 min.

- Doctor and community healer group discussion after informed briefly about the purpose of the study and written informed consent was taken. All information was recorded using digital voice recorder and note was taken. Discussion focused on your opinions about factors related to unmet need FP contraceptive methods. The recorded data were translated from local Arabic language to English language.

\section{Statistical analysis Quantitative data}

The data was collected and entered into personal computer. Statistical analysis was done using statistical package for social sciences (SPSS/version 20) software. Mean and standard deviation was calculated for numerical data. Number and percent for each category was calculated, for categorized parameters chi square test was used. The level of significant was 0.05 .

\section{Qualitative data}

The researchers used inductive analysis to analyze and explore the dominant and recurrent themes arising from the focus group data. All investigators coded the transcripts independently and then met to discuss their findings. Where coding discrepancies occurred, the group discussed and resolved these discrepancies by consensus until a common theme template was developed. Transcripts women focus groups were coded separately to explore possible differences. The main categories covering the objective behind the research were formulated. Examination for each category was carried out in order to search for subtopics and select the most useful for various ideas; this was followed by clustering the categories into themes. These themes provided the major heading for the results. 


\begin{tabular}{|c|c|c|c|c|c|}
\hline \multicolumn{6}{|c|}{$\begin{array}{l}\text { Theme: Factors related to unmet need of family planning contraceptive methods and opinions of doctors and community healer } \\
\text { toward unmet FP contraceptive methods }\end{array}$} \\
\hline Categories & $\begin{array}{l}\text { Cognitive and culture } \\
\text { factors }\end{array}$ & $\begin{array}{l}\text { Contraceptive methods } \\
\text { itself and health condition } \\
\text { factors }\end{array}$ & Sexual relation factor & $\begin{array}{l}\text { Family planning } \\
\text { services factors }\end{array}$ & $\begin{array}{c}\text { Opinions of } \\
\text { doctors } \\
\text { \&community } \\
\text { healer }\end{array}$ \\
\hline Code & $\begin{array}{l}\text { - Different types of FP. } \\
\text { - Source of information } \\
\text { about family planning } \\
\text { contraceptive } \\
\text { methods. } \\
\text { - Culture factors (have } \\
\text { bad belief about FP, } \\
\text { e.g. loop can } \\
\text { penetrate the heart) }\end{array}$ & $\begin{array}{l}\text { - Factors related to } \\
\text { contraceptive methods } \\
\text { itself (side effect from } \\
\text { contraceptive method). } \\
\text { - Factors related to health } \\
\text { condition (have any } \\
\text { disease contraindicated } \\
\text { with contraceptive } \\
\text { method). }\end{array}$ & $\begin{array}{l}\text { Factors related to } \\
\text { sexual relation (long } \\
\text { interval between } \\
\text { sexual } \\
\text { intercourse/husband } \\
\text { refused FP) }\end{array}$ & $\begin{array}{l}\text { - Factors related to } \\
\text { family planning } \\
\text { services } \\
\text { (unavailability FP } \\
\text { methods, male } \\
\text { physician). }\end{array}$ & $\begin{array}{l}\text { - Predisposing } \\
\text { factors related } \\
\text { to unmet need } \\
\text { FP } \\
\text { contraceptive } \\
\text { methods }\end{array}$ \\
\hline
\end{tabular}

\section{Results}

Part I: results of quantitative data.

Table (1): Socio-demographic characteristics of studied mothers.

\begin{tabular}{|c|c|c|}
\hline Items & Number $=\mathbf{3 7 1}$ & $\%$ \\
\hline \multicolumn{3}{|l|}{ Age ( Mother) } \\
\hline Less than 25 Years & 68 & 18.3 \\
\hline 25 to 34 Years & 186 & 50.1 \\
\hline 35 years or more & 117 & 31.5 \\
\hline \multicolumn{3}{|l|}{ Religion } \\
\hline Muslim & 272 & 73.3 \\
\hline Christian & 99 & 26.7 \\
\hline \multicolumn{3}{|l|}{ Education level } \\
\hline Illustrate & 45 & 12.3 \\
\hline Basic education & 56 & 10.1 \\
\hline Diploma & 147 & $r 9.6$ \\
\hline University & 123 & 33.1 \\
\hline \multicolumn{3}{|l|}{ Place of residence } \\
\hline Rural & 208 & 56.1 \\
\hline Urban & 163 & 43.9 \\
\hline \multicolumn{3}{|l|}{ Occupation } \\
\hline House wife & 229 & 61.7 \\
\hline Working & 142 & 38.2 \\
\hline \multicolumn{3}{|l|}{ Monthly Income } \\
\hline Not enough & 198 & 53.3 \\
\hline Enough & 165 & 44.4 \\
\hline More than enough & 8 & 2.1 \\
\hline \multicolumn{3}{|l|}{ Number of family member } \\
\hline Less than 5 & 282 & 76.1 \\
\hline More than 5 & 89 & 23.9 \\
\hline
\end{tabular}

Table (2): Menstrual and gynecological history among studied Mothers ( $n=371)$.

\begin{tabular}{|c|c|c|}
\hline Items & No & $\%$ \\
\hline \multicolumn{3}{|c|}{ Menstrual history } \\
\hline Regular & 207 & 55.7 \\
\hline Irregular & 119 & 32.1 \\
\hline Amenorrhea & 45 & 12.2 \\
\hline
\end{tabular}




\begin{tabular}{|c|c|c|}
\hline Items & No & $\%$ \\
\hline \multicolumn{3}{|l|}{ Mode of delivery } \\
\hline Normal & 122 & 32.8 \\
\hline Cesarean section & 249 & 67.2 \\
\hline \multicolumn{3}{|l|}{ Place of delivery } \\
\hline General hospital/clinic & 106 & 28.5 \\
\hline Private hospital/clinic & 265 & 71.5 \\
\hline \multicolumn{3}{|l|}{ Infant feeding } \\
\hline Breast feeding & 193 & 51.1 \\
\hline Formula feeding & 178 & 47.9 \\
\hline \multicolumn{3}{|l|}{ Number of abortion $(n=104)$} \\
\hline One & 74 & 19.9 \\
\hline Two & 20 & 5.4 \\
\hline Three & 10 & 2.7 \\
\hline
\end{tabular}

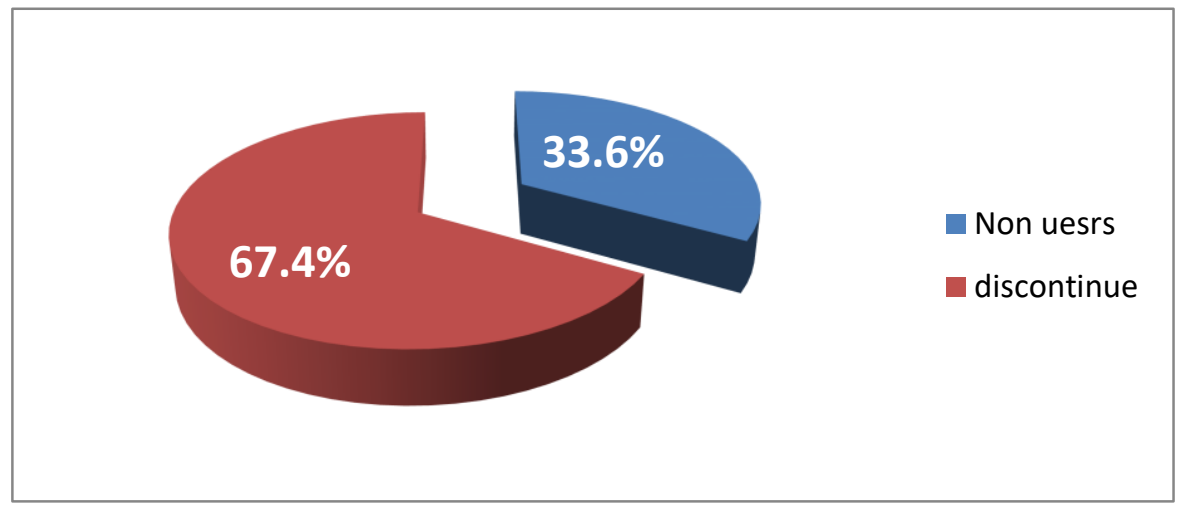

Figure (1): Types of unmet need of family planning contraceptive methods among studied mothers (n=371).

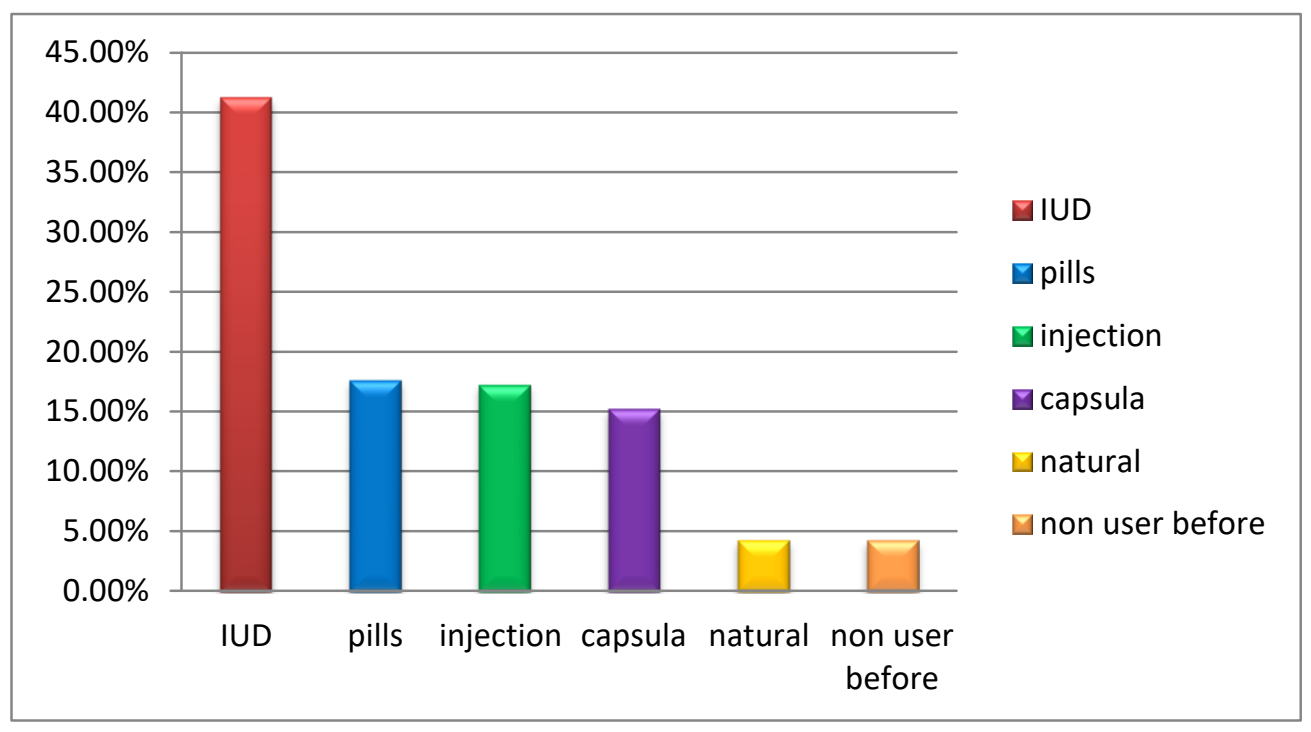

Figure (2): Distribution of previous of family planning contraceptives methods among studied mothers $(\mathbf{n}=371)$. 
Table (3): Distribution of studied mothers based on reasons for unmet need for family planning contraceptive methods $(\mathbf{n}=\mathbf{3 7 1})$.

\begin{tabular}{|l|c|c|}
\hline \multicolumn{1}{|c|}{ Reasons } & No & \% \\
\hline Wanted another pregnancy & 203 & 54.0 \\
\hline Fear from Side effect & 178 & 48.0 \\
\hline Lactation amenorrhea (last for one year) & 106 & 28.6 \\
\hline Pressure from family members (husband and other family member) & 68 & 18.3 \\
\hline Infrequent sex & 67 & 18.1 \\
\hline Not satisfied with FP services & 61 & 16.4 \\
\hline Failed to use the FP methods & 74 & 19.9 \\
\hline
\end{tabular}

Number not mutually exclusive

Table (4): Relation between reasons and unmet needs of family planning contraceptive methods $(n=371)$.

\begin{tabular}{|c|c|c|c|c|c|c|}
\hline \multirow[t]{2}{*}{ Items } & \multicolumn{2}{|c|}{$\begin{array}{c}\text { Non users } \\
(n=121)\end{array}$} & \multicolumn{2}{|c|}{$\begin{array}{l}\text { Discontinuation } \\
\quad(n=(250)\end{array}$} & \multirow[t]{2}{*}{ Total } & \multirow{2}{*}{$\begin{array}{r}\text { Chi-square } \\
\text { (P value) }\end{array}$} \\
\hline & No & $\%$ & No & $\%$ & & \\
\hline \multicolumn{6}{|c|}{ Wanted another pregnancy } & \multirow{3}{*}{$\begin{array}{c}0.16 \\
(0.69005)\end{array}$} \\
\hline No & 53 & 31.5 & 115 & 68.5 & 168 & \\
\hline Yes & 68 & 33.5 & 135 & 66.5 & 203 & \\
\hline \multicolumn{6}{|l|}{ Fear from Side effect } & \multirow{3}{*}{$\begin{array}{c}14.11 \\
(0.00017)^{*}\end{array}$} \\
\hline \begin{tabular}{l|l} 
& No
\end{tabular} & 46 & 23.8 & 147 & 76.2 & 193 & \\
\hline Yes & 75 & 42.1 & 103 & 57.9 & 178 & \\
\hline \multicolumn{6}{|l|}{ Lactation amenorrhea } & \multirow{3}{*}{$\begin{array}{c}0.15 \\
(0.70000)\end{array}$} \\
\hline No & 88 & 33.2 & 177 & 66.8 & 266 & \\
\hline Yes & 33 & 31.1 & 73 & 68.9 & 106 & \\
\hline \multicolumn{6}{|l|}{ Infrequent sex } & \multirow{3}{*}{$\begin{array}{c}0.28 \\
(0.59397) \\
\end{array}$} \\
\hline No & 101 & 33.2 & 203 & 66.8 & 304 & \\
\hline Yes & 20 & 29.9 & 47 & 70.1 & 67 & \\
\hline \multicolumn{6}{|c|}{ Not satisfied with FP services } & \multirow{3}{*}{$\begin{array}{c}13.08 \\
(0.00030)^{*}\end{array}$} \\
\hline \begin{tabular}{l|l} 
No \\
\end{tabular} & 89 & 28.7 & 221 & 71.3 & 310 & \\
\hline Yes & 32 & 52.5 & 29 & 47.5 & 61 & \\
\hline
\end{tabular}

Table (5): Relation between mothers with unmet need family planning and their socio-demographic characteristics.

\begin{tabular}{|c|c|c|c|c|c|c|}
\hline \multirow{2}{*}{ Items } & \multicolumn{2}{|c|}{ Non users } & \multicolumn{2}{|c|}{ Discontented } & \multirow[b]{2}{*}{ Total } & \multirow{2}{*}{$\begin{array}{c}\text { Chi-square } \\
\text { (P value) }\end{array}$} \\
\hline & No & $\%$ & No & $\%$ & & \\
\hline \multicolumn{6}{|l|}{ Education level } & \multirow{5}{*}{$95.3240 .001 *$} \\
\hline Illustrate & 18 & 40.0 & 27 & 60.0 & 45 & \\
\hline Basic education & 24 & 42.8 & 32 & 57.2 & 56 & \\
\hline Diploma & 44 & 29.9 & 103 & 70.1 & 147 & \\
\hline University & 35 & 28.4 & 88 & 71.6 & 123 & \\
\hline \multicolumn{6}{|l|}{ Place of residence } & \multirow{3}{*}{$\begin{array}{c}0.15 \\
(0.069604)\end{array}$} \\
\hline Rural & 72 & 34.6 & 136 & 65.4 & 208 & \\
\hline Urban & 49 & 30.0 & 114 & 70.0 & 163 & \\
\hline \multicolumn{6}{|l|}{ Occupation } & \multirow{3}{*}{$\begin{array}{c}3.81 \\
(0.05095)^{*}\end{array}$} \\
\hline House wife & 74 & 32.3 & 155 & 67.7 & 229 & \\
\hline Working & 47 & 33.0 & 95 & 67.0 & 142 & \\
\hline
\end{tabular}




\begin{tabular}{|c|c|c|c|c|c|c|}
\hline \multirow{2}{*}{ Items } & \multicolumn{2}{|c|}{ Non users } & \multicolumn{2}{|c|}{ Discontented } & \multirow[b]{2}{*}{ Total } & \multirow{2}{*}{$\begin{array}{c}\text { Chi-square } \\
\text { (P value) }\end{array}$} \\
\hline & No & $\%$ & No & $\%$ & & \\
\hline \multicolumn{6}{|l|}{ Monthly Income } & \multirow{4}{*}{$\begin{array}{l}1.163 \\
0.281\end{array}$} \\
\hline Not enough & 131 & 66.2 & 67 & 33.8 & 198 & \\
\hline Enough & 113 & 68.4 & 52 & 13023 & 165 & \\
\hline More than enough & 6 & & 2 & & & \\
\hline \multicolumn{6}{|c|}{ Number of family member } & \multirow{3}{*}{$\begin{array}{c}24.75 \\
(0.00016)^{*}\end{array}$} \\
\hline Less than 5 & 94 & 33.3 & 188 & 66.7 & 282 & \\
\hline More than 5 & 27 & 30.4 & 62 & 96 & 89 & \\
\hline
\end{tabular}

Table (1): Shows that the ranged age of studied mothers was $50.1 \%$ from 25 to 34 year, $73.3 \%$ have Muslim religion, and $61.7 \%$ of them house wife. Enough income was reported by mothers $44.4 \%$.

Concerning number of family member, $76.1 \%$ of the studied mothers had family less than five members and $56.1 \%$ residence in rural area. Regarding level diploma education was predominant among them by $39.6 \%$ and $33.1 \%$ at university level education.

Table (2): shows that $55.7 \%$ of the studied mothers have a regular menstrual cycle and $67.2 \%$ of them have the last mode of delivery was cesarean section. As regards feed their babies $51.1 \%$ by breast feeding. Figure (1): The figure displays $33.6 \%$ of the studied mothers were not using any of family planning methods although they had no desire for more children (nonuser) and $67.4 \%$ of them had users in the past and stopped of using contraceptives methods (discontinuation).

Figure (2): The figure shows that the most common family planning contraceptive methods used by studied discontinuation mothers are IUD followed by pills, injection, and under skin capsule.

Table (3): Illuminates that the wanted another pregnancy was the most commonly cited reason for unmet need family contraceptive methods while fear of side effects and lactation amenorrhea was the second most common reasons $(54 \%, 48 \%$ \& $28.6 \%$ respectively).

As regards not satisfied with family planning services was reported by $16.4 \%$ of mothers as the main reason for non-use. There another reason reported by mothers such as infrequent sex and failed to use the FP methods (18.1\% and $19.9 \%$ respectively).

Table (4): indicates that there were statistically significant $(\mathrm{P}<0.001)$ between studied mothers (nonuser and discontinuation) and fear from contraceptive methods side effect, unsatisfaction from family planning services. The table also reveals there were no statistically significant between wanted pregnancy, infrequent sex and lactation amenorrhea reasons with unmet need family planning contraceptive methods among studied mothers.
Table (5): indicates that there were statistically significant $(\mathrm{P}<0.001)$ between studied mothers (nonuser and discontinuation) and educational level, occupation and number of family members. The table also reveals there were no statistically significant between place of residence and monthly income and unmet need family planning contraceptive methods among studied mothers.

\section{Part II: Results of qualitative data}

The emerged raw qualitative data clustered under the following themes

- Cognitive and culture factors

- Contraceptive methods itself and health condition

- Factors Sexual relation factors

- Family planning services factors:

- Opinions of doctors and community healer in family health center toward unmet family planning contraceptive methods among mothers.

Cognitive and culture factors

Most of the mother reported that they did not know the exact types of family contraceptive methods. The most of women awarded of the intrauterine contraceptive devices, pills, progesterone injections as a method of spacing birth. The source of information among women about contraception was social circle, friends and sometimes pharmacists. Most of the women did not know the benefits of spacing between pregnancy and another on the health, economic and social status of individuals, the family, and society and the survival of mothers and children. They want to be the number of children in the family from three to four children.

$$
\begin{aligned}
& \text { - للأسف طبيب الوحدة لا يشرح الوسائل وأعراض كل منها } \\
& \text { والأنسب لنا }
\end{aligned}
$$

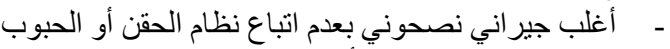

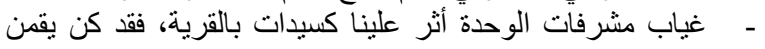

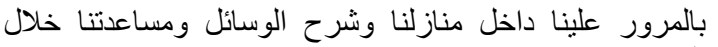

$$
\begin{aligned}
& \text { المتابعة }
\end{aligned}
$$

Most women have common beliefs such as IUDs going to the heart, injections lead to infertility and contraceptive pills lead to cancer. And that modern contraceptives harm the health of the mother and some of the women have the opinion that giving birth at the young age better than reproduction in the old 
age. Women also said discussing sexual behavior with a male doctor was very difficult.

$$
\begin{aligned}
& \text { كتير من جير اني و اصحابي قالوا ان ( اللولب بيسرح علي القلب }
\end{aligned}
$$

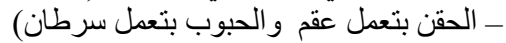

$$
\begin{aligned}
& \text { الخلفة في الصغر يريح الكبر }
\end{aligned}
$$

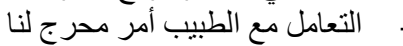

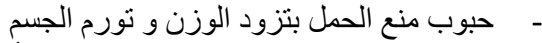

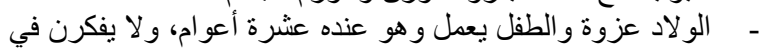

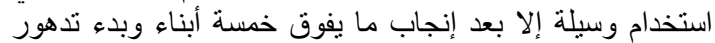

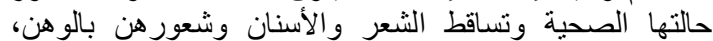

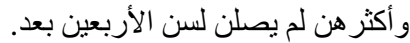

$$
\begin{aligned}
& \text { - أغلبنا يتزوج مبكرا، وعمر المنزوجات لا يتعدى عشرين عامان }
\end{aligned}
$$

II-Contraceptive methods itself and health condition:

Some women report that they have failed to use contraceptives methods due to misuse, forgetfulness and waiting for menstruation and others reasons for unmet use of contraceptive methods due to side effects of the method and complications such as severe pain in the chest or abdomen or arms and frequent and severe headache, severe bleeding during or after menstruation and severe depression with mood disorder.

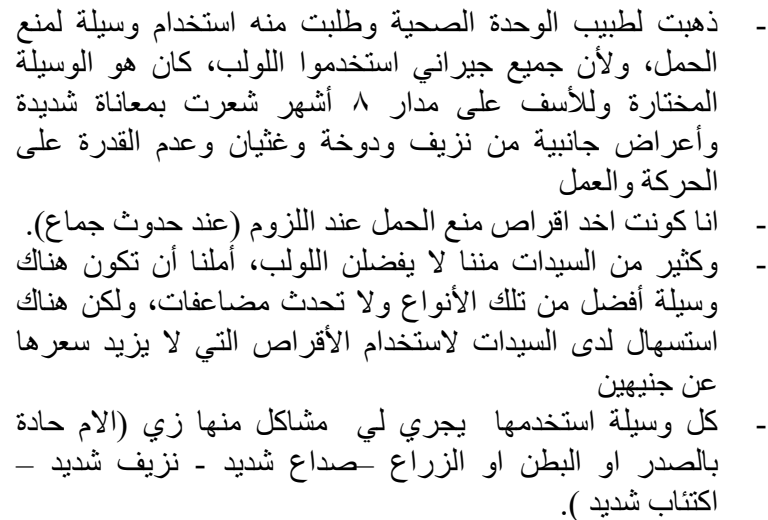

Some women stopped contraceptivehod method due to of health conditions such as the incidence of varicose veins and disorders in hormones of the body such as prolactin hormone or have been discontinued by the order of the treating physician. In this case, women reported using natural contraception, such as ovulation period or ejaculation outside the vagina. - عندي دوالي بالرحم والطبيب نصحني بعدم استخدام اي وسيلة منع

ـ الطبيب اشترط عليا مو افقة الزوج لاخذ الوسيلة و انا مش عرفه اية

ـ المثانه بتعتي عصبية لما كونت مركبه اللولب فماكنتوش بقدر احتكم

\section{III-Sexual relation factors}

$$
\text { في البول }
$$

Most of women have reported that absence of intercourse/ long intervals between intercourses. Besides contraceptive methods had effect on sexual relation with his husband due to long duration of menses days, husband fear from IUD during sexual intercourse. Also some women reported that husband refuse to use condom because it affects sexual satisfaction during intercourse.

$$
\begin{aligned}
& \text { - - نزول الدورة الشهرية نقط و عدم انتظامها. }
\end{aligned}
$$

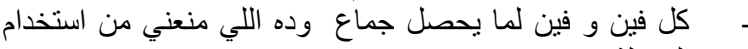

$$
\begin{aligned}
& \text { الوسيلة } \\
& \text { اللولب كان يزود من ايام الدورة اكثر من اسبوع و اثناء الفتره }
\end{aligned}
$$

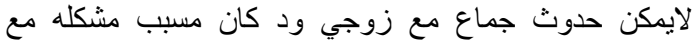

$$
\begin{aligned}
& \text { زوجي. لما شيلت اللولب جاع ماول زوجي زوجي في استخدام الحاجز }
\end{aligned}
$$

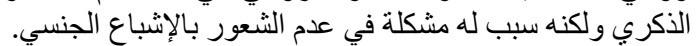

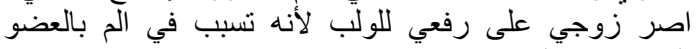

$$
\begin{aligned}
& \text { الأكري عند الجماع }
\end{aligned}
$$

IV-Family planning services factors:

After asking about access family planning services, the majority of women stated that poor quality of service, previous bad experience with the facility, service provider's attitude, and lack of privacy during examinations, shortage of stock. While another women group reported that there was no source of information regarding contraceptive methods and how to select suitable methods. The Internet is the only source of information for this topic.

$$
\begin{aligned}
& \text { - انا بخاف اروح مركز تنظيم الأسرة نتيجة الخبرة السيئة للأخرين }
\end{aligned}
$$

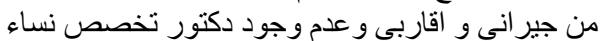

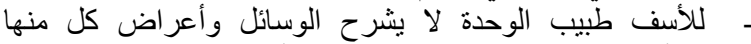

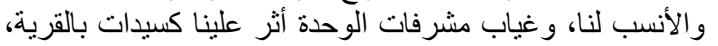

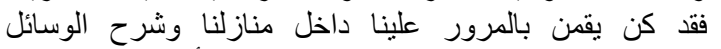

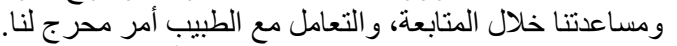

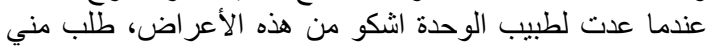

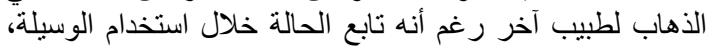

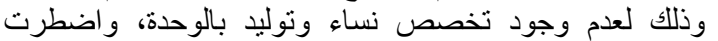

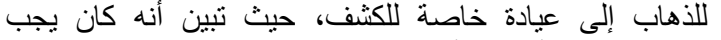

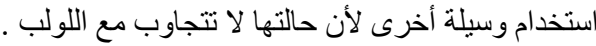

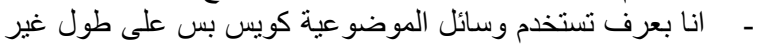

$$
\begin{aligned}
& \text { منوفرة بالوحدة (العجلة / اللبوس المهوفيلي). }
\end{aligned}
$$

V-The opinions of doctors and nurses towards women unmet family planning contraceptive:

The family planning doctors reported that the women refuse the advice of the doctor and rely on the experiences of neighbors and relatives and grandfather. In addition the early marriage, illiteracy, ignorance, and absence of family planning campaigns behind population growth. Family planning campaigns have disappeared and must be returned and increased funding for more variety of means

$$
\begin{aligned}
& \text { - السيدات يرفضن نصيحة الطبيب، ويعتمدن على خبرات الجارة } \\
& \text { و والأقارب و الحماة برفن }
\end{aligned}
$$

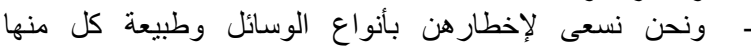

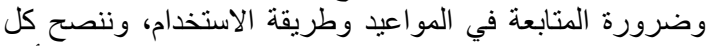

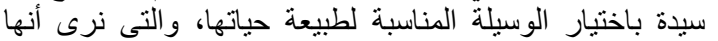

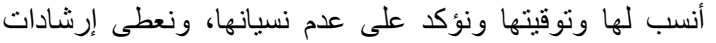

$$
\begin{aligned}
& \text { بالوسيلة وطريقة عملها ومو اعيد تناو لها }
\end{aligned}
$$

As for the side effects of contraceptive methods doctors said there are side effects of contraceptive methods, but depending on the health status, the contraceptive pills may cause bleeding, obesity, nausea, and vomiting, as well as the IUD may cause 
severe infections of the uterus, so the women should detect and follow-up and continuing to treatment. Most of nurses reported that most common problems facing him the intransigence of couples and the intervention of protectors in the decision to reproduce directly

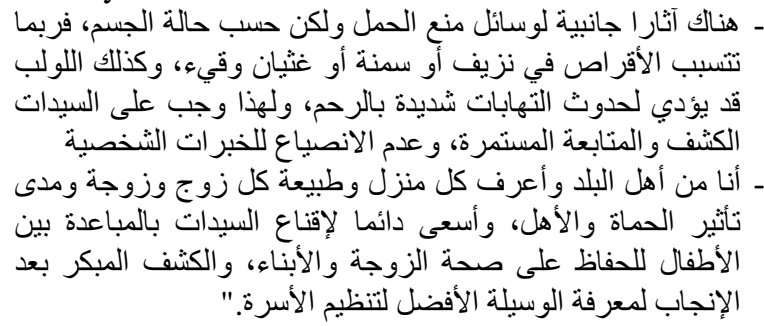

\section{Discussion}

According to Egyptian MOH statistics, about 8 to 10 young married women wanted no additional children or wanted to delay the next birth for at least 2 years, yet a sizeable proportion did not use contraception(Jain et al., 2014). The gap between stated preference and actual behavior is a measure of what demographers label "unmet need". Also, more than half the women with unmet need indicated that they intended to use family planning contraceptive methods but were unable to do so(Jain \& Winfrey, 2017).

The present study shows that more than half of studied mothers ranged age was from 25 to 34 year, and have a regular menstrual cycle. Nevertheless, the current study showed that less than one-third of studied mothers after postpartum who have no desire to get pregnant in the next two years following birth but do not use family planning contraceptive methods while there were more than two third do not use family planning contraceptives for want to another pregnancy. This finding supported by Elweshahi et al., (2017) who studied "Unmet need for postpartum family planning in Alexandria, Egypt" reported that $16.28 \%$ of women under study sample at 12 months post-partum who have no desire to get pregnant in the next two years following birth are not using a contraceptive.

Also study done by Sudha et al., (2017) who studied "Unmet need for contraception among urban women: a cross sectional study in Puducherry, India" founded that nearly most of the women reported having used any method of contraceptive at least once and one third of them were found to have unmet need for family planning.

The current study mentions also that the most common previous family planning contraceptive methods used by mothers under the study were IUD contraceptive methods and hormonal contraceptive methods. These results similarly with El Shazly et al., (2016) who studied" Discontinuation of contraception in rural and urban areas in Menoufia Governorate Egypt" founded that IUD, pill, and injectable are the most widely used methods for family planning among young married women. These finding contraindicated with Kashyap et al., (2017) who studied "Pattern of family planning practices among Janani Suraksha Yojana beneficiaries: Central Uttar Pradesh, India" reported that the female sterilization was the most widely accepted method by contraceptive users followed by IUDs.

Concerning the reasons for unmet need of family contraceptive methods, the present study showed that the first reason for unmet need for family planning contraceptive methods was desire for another child, fear from side effects of contraceptives as well as discontinuation shortly after usage, followed by lactation amenorrhea is considered a method of birth control only during the first sixth months after birth and under specific circumstances, it was cited as the main reason for non-use of a contraceptive. The same reasons in the present study were found in surveys by Sedgh \& Hussain, (2014) in Africa, Asia, and Latin America and the Caribbean studied to identify reasons for contraceptive nonuse among women having the unmet need for contraception. Also these finding supported by Shah et al., (2007) who studied" Reasons and correlates of contraceptive discontinuation in Kuwait" reported that the major reason for discontinuation of family planning contraceptive use, currently the leading method, was the desire for another child. However, and stopped contraceptives method after 36 months did so for health reasons.

The present study provides rich sources for both quantitative as well qualitative data which could be used in developing strategies to educate the mothers and their husband family planning contraceptive methods in order to prevent future health problems.

Overall the most important qualitative findings of the current study showed that, the majority of studied mothers found to have low level of knowledge and lack of awareness regarding family planning contraceptive methods such types, right using of contraceptive method and benefits of spacing between pregnancies. The most of them reported that there is no source of information about FP some of them reported using internet as a sources of information but without interest. The main causes founded for low level of knowledge about FP among participants was source of information depend on social circle, friends and sometimes pharmacists.

A study done by Tilahun et al., (2013)who studied "family planning knowledge, attitude and practice among married couples in jimma zone, ethiopia" founded that knowledge and awareness of 
contraceptives are not sufficient to ensure that contraceptive needs are met. Another Study done by (Sharma et al., 2017), who studied "Knowledge and attitude towards contraceptive methods for spacing and decision making factors regarding its use in postpartum women in India" reported that the level of awareness about spacing contraception was incorrect use. The most frequent source of information was social circle and friends.

The present study explored the various types of reported factors for both the nonusers and discontinuation. These factors include cultural factors, factors related methods itself, and health condition factors, family planning services factors and sexual relationship factors with her husband. The majority of the unmet need of FP said they have false beliefs toward injections cause infertility and contraceptive pills lead to cancer. The modern contraceptives harm the health of the mother to have children and intended to use FP methods in the future.

In the study done by El Shazly et al., (2016) who studied "Discontinuation of contraception in rural and urban areas in Menoufia Governorate", found that unmet need of FP and the women who had discontinued use said they intended to have children and intended to use FP methods in the future. These results presented contradicted between what the women want and what they really do. This could be because many Egyptian women want to have greater control over reproductive decisions, but they lack the knowledge and need proper counseling. Such findings could illustrate that women's intention reflects their ability to respond to health education sessions about family planning according to whether their needs are met

In study do by Eltomy et al., (2013) who studied "Barriers affecting utilization of family planning services among rural Egyptian women" found that the cultural, and demographic factors were statistically significant factors that affect unmet need of family planning.

Concerning the factors related to methods itself, Sudha et al., (2017) in India confirmed the present study and asserted that the women provided various reasons for their fear from contraceptive side effect such as bleeding, nausea, headache, low back pain, and depression with mood disorder. Study by Yeatman et al., (2013)in Indonesia who reported that among women using contraception, the majority of unintended pregnancies occurred as a result of inconsistent or incorrect use of the method. Such finding related to the method itself, most of the women who had unmet need family planning contraceptive had a desire to have a more effective method.
Regarding factors related to health condition, Our findings are supported by evidence from Ghana, Kenya, Cameroon, Jamaica, and Senegal indicating that uterus varicose vein are commonly in women told they must do not back to contraceptive method Tolley et al., (2005). Study by Bertrand et al., (1995) who studied" Access, quality of care and medical barriers in family planning programs" reported that there are a number of different types of health condition factors such as women's age, their parity or the consent of their spouse. In addition varicose veins, epilepsy or tuberculosis is contraindications to the use of hormonal methods.

The current study also showed that the factors of unmet need family planning contraceptive related to sexual relations with her husband. This was confirmed in another study by Sedgh et al., (2007) in Egypt founded that the discontinuation of the last contraceptive method was related to the husband's disapproval. Also study by El-koury et al., ( 2016) who studied "counseling women and couples on family planning" reported that counseling women lead to the same favorable final outcomes as couples counseling while there were no any benefits of involving men in family planning counseling. Another study by Elweshahi et al., (2017) who studied "unmet need for postpartum family planning in Alexandria, Egypt" founded that the pressure from the surroundings as opposed to using a contraceptive by her husband or relatives for personal due to false beliefs the main factor for unmet need family planning methods.

The factors related to family planning services were the most reported ones. These findings similar with studies in Nepal and in Jordan (Hasna, 2006), where the researchers related the hesitation to seek out FP services to administrative barriers, which included problems in the health-care delivery system and perceptions of health-care providers, especially their FP counseling skills.

Several studies on unmet need family planning give insight into both the adequacy of family planning services and client satisfaction with methods. Similarly, in an earlier study, those authors discuss how high rates of discontinuation may signal discontent with the method and/or family planning service provision, and that high failure rates likely indicate inadequate counseling (Jain et al., 2014, Kashyap et al., 2017, Ahmed et al., 2016). In the study done by(Tolley et al., 2005) who studied "The impact of menstrual side effects on contraceptive discontinuation: findings from a longitudinal study in Cairo, Egypt" reported that the attitude of health providers towards particular contraceptive methods in developing countries has been shown to influence continuation rates among women. 


\section{Conclusion}

Based on the findings of the present study and research questions, it was found showed that less than one-third of studied mothers after postpartum who have no desire to get pregnant in the next two years following birth but do not use family planning contraceptive methods while there were more than two third discontented family planning contraceptives. The most studied mothers used IUD contraceptive methods and hormonal contraceptive methods. The main reasons for unmet need for family planning were desire to another child, and fear from contraceptive side effect. Unmet need for family planning contraceptive methods associated with knowledge, culture, contraceptive methods itself, and factors related to sexual relation and family planning services factors.

\section{Recommendations}

Distribute copies of family planning booklet, flayers, and pictures for mothers at different Family Health centers at Ismailia city, Egypt. Further qualitative research with women, community leaders and health providers are required to clarify in depth the real barriers and challenges against achievement of zero percentage of unmet need for family planning and raise recommendations to be the basis for a community based intervention studies

\section{Limitations of the study}

The sample in the present study was nonrepresentative for unmet family planning contraceptive methods and results cannot be generalized. Lack of enough data for users of contraceptives was a barrier towards identification of all possible determinants of having unmet need to family planning contraceptive methods.

\section{References}

1. Ahmed, A., Mohamed, N., \& Mahmmed, T., (2016): Effect of counseling program on early postpartum breast feeding by nursery mother. International Journal of Advanced Nursing Studies, 5, 117-121.

2. Ayiasi, R., Muhumuza, C., Bukenya, J., \& Orach, C., (2015): The effect of prenatal counselling on postpartum family planning use among early postpartum women in Masindi and Kiryandongo districts, Uganda. Pan African Medical Journal, 21.

3. Choi, Y., Fabic, M., \& Adetunji, J., (2016): Measuring Access to Family Planning: Conceptual Frameworks and DHS Data. Studies in family planning, $47,145-161$.

4. CLELAND, J., HARBISON, S. \& SHAH, I. H. 2014. Unmet need for contraception: issues and challenges. Stud Fam Plann.
5. EL-moselhy, E., Moftah, F., Darwish, M., \& Rahma, A., (2017): Trends and determinants of contraceptive use among young (15-24 year) married women: a secondary analysis based on the 2008 and 2014 Egypt Demographic and Health Surveys. The Egyptian Journal of Hospital Medicine, 66, 170-187.

6. El-khoury, M., Thornton, R., Chatterji, M.,Kamhawi, S., Sloane, P., \& Halassa, M., (2016): Counseling Women and Couples on Family Planning: A Randomized Study in Jordan. Studies in family planning, 47, 222-238.

7. EL shazly, H., Emara, M., \& AL agha, R., (2016): Discontinuation of contraception in rural and urban areas in Menoufia Governorate. Menoufia Medical Journal, 29, 996.

8. ELtomy, E., Saboula, N., \& Hussein, A., (2013): Barriers affecting utilization of family planning services among rural Egyptian women, 25,28 .

9. ELweshahi, H., Gewaifel, G., Sadek, S., \& ELsharkawy, O., (2017): Unmet need for postpartum family planning in Alexandria, Egypt. Alexandria Journal of Medicine.

10. Hasna, F., (2006): Utilization of family planning services in the governorate of Zarqa, Jordan. Journal of Transcultural Nursing, 17, 365-374.

11. Jain, A., Mahmood, A., \& Sathar, Z., (2014): Reducing unmet need and unwanted childbearing in Pakistan: evidence from a panel survey. Stud Fam Plann.

12. Jain, A., \& Winfrey, W., (2017): Contribution of Contraceptive Discontinuation to Unintended Births in 36 Developing Countries. Studies in Family Planning.

13. Kashyap, S., Kumari, R., Masood, J., Verma, S., Jain, S., \& Kumar, A., (2017): Pattern of family planning practices among Janani Suraksha Yojana beneficiaries: Central Uttar Pradesh, India. International Journal Of Community Medicine And Public Health, 2, 535-539.

14. Machiyama, K., \& Cleland, J., (2014): Unmet need for family planning in Ghana: the shifting contributions of lack of access and attitudinal resistance. Stud Fam Plann.

15. Mohsen, M., EL-abbassy, A., \& Khalifa, A., (2016): Effect of application of a Health Belief Model on changing mothers' beliefs regarding birth spacing in rural areas. Clinical Nursing Studies, 4, p54.

16. Sarayloo, K., Moghadam, Z., Mansoure, J., Mostafa, H., \& Mohsen, S., (2015): The impact of an educational program based on BASNEF model on the selection of a contraceptive method in women. Iranian journal of nursing and midwifery research, 20, 171. 
17. Sedgh, G., \& Hussain, R., (2014): Reasons for contraceptive nonuse among women having unmet need for contraception in developing countries. Stud Fam Plann.

18. Sedgh, G., Hussain, R., Bankole, A., \& Singh, S., (2007): Women with an unmet need for contraception in developing countries and their reasons for not using a method. Occasional report, 37, 5-40.

19. Shah, N., Shah, M., Chowdhury, R., \& Menon, I., (2007): Reasons and correlates of contraceptive discontinuation in Kuwait. The European Journal of Contraception \& Reproductive Health Care, 12, 260-268.

20. Sharma, J., Dorairajan, G., \& Chinnakali, P., (2017): Knowledge and attitude towards contraceptive methods for spacing and decision making factors regarding its use in postpartum women. International Journal of Reproduction, Contraception, Obstetrics and Gynecology, 4, 750-754.

21. Sitruk-ware, R., Ramarao, S., Merkatz, R., \& Townsend, J., (2016): Risk Of Pregnancy In Breastfeeding Mothers: Role Of The Progesterone Vaginal Ring on Birth Spacing. European Medical Journal of Reproductive Health.

22. Sudha, V., Vrushabhendra, H., Srikanth, S., \& Suganya, E., (2017): Unmet need for contraception among urban women: a cross sectional study in Puducherry. International Journal Of Community Medicine And Public Health, 4, 1494-1499.

23. Tilahun, T., Coene, G., Luchters, S., Kassahun, W., Leye, E., Temmerman, M. \& Degomme, O., (2013): Family planning knowledge, attitude and practice among married couples in Jimma Zone, Ethiopia. PloS one, 8, e61335.

24. Tolley, E., Loza, S., Kafafi, L., \& Cummings, S., (2005): The impact of menstrual side effects on contraceptive discontinuation: findings from a longitudinal study in Cairo, Egypt. International family planning perspectives, 15-23.

25. World Health Organiztion (2012): Unsafe abortion incidence and mortality: global and regional levels in 2008 and trends during 19902008.

26. Vural, F., Vural, B. \& Cakiroglu, Y. (2016): The Effect of Combined Antenatal and Postnatal Counselling on Postpartum Modern Contraceptive Use: Prospective Case-Control Study in Kocaeli, Turkey. Journal of clinical and diagnostic research: JCDR, 10, QC04.

27. Yeatman, S., Sennott, C. \& Culperpper, S. (2013): Young women's dynamic family size preferences in the context of transtioning fertility. Demography. 